acquaint themselves with the improvements continually made in this branch of their science. This could best be done by the establishment at convenient places of collections designed to exhibit the progress of photography as applied to astronomical observations.

The Harvard College Observatory has some special advantages for forming such a collection, since it already possesses many of the early and historically important specimens which would naturally form part of the series. Among these may be mentioned four series of daguerreotypes and photographs of various celestial objects taken at this Observatory. These series were respectively undertaken in $1850,1857,1869$, and 1882 .

At present, the astronomers of the United States have no ready means of comparing their own photographic work with that done in Europe, or even with that of their own countrymen. The proposed collection of photographs, so far as it could be rendered conplete, would greatly reduce the difficulty.

It is therefore desired to form, at the Harvard College Observatory, a collection of all photographs of the heavenly bodies and of their spectra which can be obtained for the purpose; and it is hoped that both European and American astronomers will contribute specimens to this collection. Original negatives would be particularly valuable. It may happen that some such negatives, having slight imperfections which would limit their value for purposes of engraving, could be spared for a collection, and would be as important (considered as astronomical observations) as others photographically more perfect. In some cases, astronomers may be willing to daposit negatives taken for a special purpose, and no longer required for study, in a collection where they would retain a permanent value as parts of an historical series. Where photography is regularly employed in a continuous series of observations, it is obvious that specimen negatives only can be spared for a collection. But in such cases it is hoped that some duplicates may be available, and that occasional negatives may hereafter be taken for the purpose of being added to the collection, to exhibit.recent improvements or striking phenomena.

When negatives cannot be furnished, glass positives, taken if possible by direct printing, would be very useful. If these also are not procurable, photographic prints or engravings would be desirable.

In connection with the photographs themselves, copies of memoirs or communications relating to the specimens sent, or to the general subject of astronomical photography, would form an interesting supplement to the collection. A part of the contemplated scheme will involve the preparation of a complete bibliography of the subject, including a list of unpublished photographs not hitherto mentioned in works to which reference may be made.

The expense which may be incurred by contributors to the collection in the preparation and transmission of specimens will be gladly repaid by the Harvard College Observatory when desired.

EDWARD C. PICKERING, Director of the Harvard College Observatory

Cambridge, Mass., February 2 I

\section{DARWIN AND COPERNICUS 1}

$T^{H E}$ $\mathrm{EE}$ losses by death which natural science has sustained during the past year are unusually heavy. The fertile and ingenious mathematician who for more than a generation held a leading position among French men of science as the publisher of one of the best-known mathematical journals; the chemist who, by the first organic synthesis, helped to dispel the illusion of vital

I Address by Prof. E. Du Bois Reymond at the anniversary meeting of the Berlin Academy of Sciences. energy; the physiologist who solved one of the oldest problems of humanity-are men whose death leaves a void not easily filled up. But the lustre of even such names as Liouville, Wöhler, and Bischoff pales before that of the first on our list, Charles Darwin. Nearly every learned Society in existence has publicly deplored his loss. As this Academy has not hitherto found a fitting opportunity for doing so, it is necessary to add a few words to the formal mention of his decease, to show that we also appre:iate the greatness of the man and of the loss science has sustained in him.

To say anything fresh concerning him will only be possible when the lapse of time and the progress of science have opened up new points of view; and the speaker, who has often had occasion to discuss Darwin before this Academy, finds it especially difficult not to repeat himself, the more so as opinions of his work are still somewhat apt to be influenced by personal feeling.

Darwin seems to me to be the Copernicus of the organic world. In the sixteenth century Copernicus put an end to the anthropocentric theory by doing away with the Ptolemaic spheres and bringing our earth down to the rank of an insignificant planet. At the same time he proved the non-existence of the so-called empyrean, the supposed abode of the heavenly hosts, beyond the seventh sphere, although Giordano Bruno was the first who actually drew the inference.

Man, however, still stood apart from the rest of animated beings-not at the top of the scale, his proper place, but quite away, as a being absolutely incommensurable with thein. One hundred years later Descartes still held that man alone had a soul and that beasts were mere automata. Notwithstanding all the labour of naturalists since the days of Linnæus, notwithstanding the resurrection of vanished genera and species by Cuvier, the theory of the origin and interdependence of living things, which was almost universal five-and-twenty years ago, was only equalled in arbitrariness, artificiality, and absurdity by the celebrated theory of Epicycles, which caused Alfonso of Castile to exclaim, "If God had asked my advice when he created the world, I should have managed things much better."

"Afflavit Darwinius et dissipata est," would, alluding to the above-mentioned theory, be a fitting inscription for a medal in honour of the "Origin of Species." For now all things were seen to be due to the quiet development of a few simple germs; graduated days of creation gave place to one day on which matter in motion was created; and organic suitability was replaced by a mechanical process, for as such we may look on natural selection, and now for the first time man took his proper place at the head of his brethren.

We may compare Copernicus's student days at Bologna with Darwin's voyage in the Beagle, and his retired life at Frauenburg with Darwin's in his Kentish home, up to the time when the appearance of $\mathrm{Mr}$. Wallace's work caused him to break bis long silence. Here happily for Darwin the parallel ends. Many circumstances combined in Darwin's case to render his task easier and insure his ultimate triumph. Botany and zoology, morphology, the theory of evolution, and the study of the geographical distribution of plants and animals, had advanced far enough to allow of general conclusions being drawn from them; Lyell's sound sense had freed geology from the hypotheses which disfigured it, and introduced the idea of uniformity into science. The doctrine of the conservation of energy bad been put on a new basis, and extended so that in combination with astronomical observation it gave rise to entirely new views of the history and duration of the universe. The doctrine of vital energy had been proved to be untenable on closer investigation. An unusually dry season had some years earlier led to the discovery of the so-called lake-dwellings in the bed of one of the 
Swiss lakes, whereby prehistoric research was quickly extended and developed. Though many links are still missing, we may fairly consider the knowledge of the existence of primeval man as the beginning of the longlooked for connection between him and the antbropoids on the one hand, and between them both and their common progenitors on the other. In a word the time had come for the publication of the "Descent of Man"; that is why an opinion on the nature of man, which differs from all former ones fully as much as the system of Copernicus, of which it is the complement, differs from that of Ptolemy, found such ready and general acceptance.

How different was the fate of Copernicus! "Copernicus," says Poggendorff, "is, and will ever remain, a brilliant star in the firmament of science; but he rose at a time when the horizon was almost entirely obscured by the mists of ignorance. . . . The Ptolemaic system was too ancient and too much venerated to be easily displaced." Copernicus's teaching met with but scant appreciation for the first fifty years after its publication; even Tycho. Brahe opposed it ; it can therefore scarcely cause surprise that Luther rejected it, that Giordano Bruno died at the stake for his advocacy of it, while the less steadfast Galileo was forced to renounce it.

Notwithstanding the pessimism of our speculative philosophers, who deny all progress because they contribute nothing towards it, Darwin's lot was happier than that of the great reformer of astronomy. While Copernicus could only feast his eyes on the first printed copy of his work as he lay on his deathbed because he had not dared to publish it sooner, although he had completed it some years before, Darwin survived the appearance of his nearly a quarter of a century. He witnessed the fierce struggles its appearance at first gave rise to ; its ever increasing acceptance and its final triumph, to which he, cheerful and active to the last, greatly contributed by a long series of admirable works.

While the Holy Inquisition persecuted the followers of Copernicus with fire and sword, Charles Darwin lies buried in Westminster Abbey among his peers, Newton and Faraday.

\section{SINGING, SPEAKING, AND STAMMERING ${ }^{1}$}

\section{III.-STAMMERING}

A

TER the emotional and intellectual sides of human utterance, what may be termed its pathological aspect was consideref. Imperfections of speecb, though serious hindrances to intercourse, are unfortunately not uncommon. It is not easy to realise how common they are. The statistics collected by Colombat point to the conclusion that about two persons in every thousand stammer, an estimate which is exactly borne out by official returns obtained in Prussia. This would make two and a half millions of stammerers in the world. But it is hardly fair to argue from the higher to the lower races of mankind, for stammering, like hysteria, is undoubtedly a disease of advanced civilisation. It was unknown among the North American Indians in Catlin's time ; Livingstone says he never met with a case among the Negroes, and Cameron is stated to have confirmed the observation. It is uncommon in Spain and Italy, but reaches its maximum in highly-educated Prussia and in this country. "No nation in the civilised world," says Mr. Deacon, who has been already quoted, "speaks its language so abominably as the English.'

Stammering appears to be commoner among males than females.

Laboured distinctions have been made between the two words, to stammer and to stutter, by which the infirmity is denoted. These seem to be wholly unnecessary, since they are practically synonymous. Both words contain an

I Abstract by the Author of three Lectures at the Royal Institution, by W. H. Stone M.B., F.R.C.P. Concluded from P. 533 . imitation of the defect itself. They probably reach us through the German language, but the ultimate root is the Greek $\Sigma \tau \epsilon i \beta \omega$, and the fundamental meaning movement abruptly checked. There is indeed a whole series of allied old English words such as lag, dag, jog, shog, stag, and cognates are stab, stagger, stamp. In some parts of the country a horse is said to stammer when he trips in walking. Bacon, in his "Natural and Experimental History," says: "Many stutters are very cholerick, choler inducing dryness of the tongue." It was long ago noticed by Sir Charles Bell in his Bridgwater Treatise, that speech, like writing, walking, and other functions of life, is a coordinate muscular act involving many nerves as well as muscles, but which, having been learned early, has become so automatic that the directing of special attention to it rather hinders than assists in its easy performance. Indeed the act not only $i$ volves the mechanism of speech proper, but also that of thought and ideation, as well as that of hearing, by means of which the sounds emitted are discriminated. It thus may never be developed, as in idiocy, of which the failure to acquire it is often the first sign: or in congenital deafness, which is the precursor of dumbness. It may also disappear entirely or partially in conditions of cerebral lesion known to medical men under the titles of aphasia, aphemia, and amnesia, often accompanying hemiplegia of the right side of the bodv. Real stammering may be produced by mental strain or shock, and persist through life. Such cases are rare, but the lecturer has been allowed to refer in general terms to one which can easily be verified-that of a clergyman who, after being overtaxed physically and mentally during one of the earlier cholera epidemics, began to stammer, and though now an old man, has never since been able to officiate in the service of the Church. Mr. Plumptre, in his lectures on Elocution, quotes even a more remarkable case from Di. Mariano Semmola, where the loss of articulation was accompanied by convulsive movements, and instantly restored by bleeding.

The failure of coordination requisite to accomplish so complex a function may occur anywhere in the apparatus involved. Hence there are many forms of the affection, which may be roughly classified into four: (I) at the glottis, (2) at the isthmus of the fauces, (3) between the tongue and palate, (4) at the lips and posterior nares. The late Charles Kingsley, in his article quaintly named "The Irrationale of Speech," published in Fraser's Magazine for July, 1859, calls these four variations abuses of breath, jaw, tongue, and lips. But these by no means exhaust the catalogue of physical infirmities affecting speech, though being the most completely functional they fall strictly within the definition of stammering. Idiocy, deafness, and paralysis have been named, and to them may be added spasm, as in some cases of St. Vitus's dance. There are also several malformations and acquired disorders, such as (I) large or unsymmetrical tongue or tonsils, (2) cleft palate, (3) obstructed nasal passages, (4) high roofed mouth, (5) prominent and everted incisor teeth, which interfere with distinct articulation; besides the kindred bad habits called lisping, burring, and thickness of speech. Even then the list is not completed ; for we have to add ( $\mathrm{I}$ ) a sort of hyperæsthesia or nervousness which occurs in some persons when they are out of health, and which disappears under better hygienic conditions; (2) tricks and bad habits, of which a flagrant example occurred some years ago, when a mania for transposition of words seized the younger and more thoughtless of the generation. A mutton chop, for instance, became a chutton mop, and one heard of the Chishop of Bicester, who had a sit of fickness through eating acon and beggs. In many cases the habit became uncontrollable, and is handed down to fame by the lady aunt of "Happy Thoughts," in Punch, who corrected errors of speech by reference to "Dixon's Johnsonary." (3) Mimicry, which produces a sort of contagiousness in 